\title{
Controls on fluvial evacuation of sediment from
}

\section{earthquake-triggered landslides}

\author{
Jin Wang ${ }^{1,2,3}$, Zhangdong Jin ${ }^{1,4}$, Robert G. Hilton ${ }^{2}$, Fei Zhang ${ }^{1}$, Alexander L. \\ Densmore ${ }^{2,5}$, Gen $\mathrm{Li}^{\mathbf{6}}$, and A. Joshua West ${ }^{6}$ \\ ${ }^{1}$ State Key Laboratory of Loess and Quaternary Geology, Institute of Earth \\ Environment, Chinese Academy of Sciences, Xi'an 710075, China \\ ${ }^{2}$ Department of Geography, Durham University, Durham, DH1 3LE, UK \\ ${ }^{3}$ University of Chinese Academy of Sciences, Beijing 100049, China \\ ${ }^{4}$ Institute of Global Environmental Change, Xi'an Jiaotong University, Xi'an 710049 , \\ China \\ ${ }^{5}$ Institute of Hazard, Risk and Resilience, Durham University, Durham, DH1 3LE, \\ $U K$ \\ ${ }^{6}$ Department of Earth Sciences, University of Southern California, Los Angeles, CA \\ 90089, USA
}

\section{Grain Size Distribution of Landslide Deposits}

In this study, we use published measurements of the grain size distribution of landslide deposits formed during the 2008 Wenchuan earthquake (Table DR3) (Wang et al., 2011; Chen et al., 2012; Wang et al., 2012; Zhuang et al., 2012; Wang et al., 2013; Yu et al., 2013). Full details of methods can be found in these publications. Here, for summary, the procedure described by Wang et al. (2013) is provided. The grain size distribution of landslide sediment was analyzed by sieving and photography at 11 locations on the Tianchi landslide dam deposit. The area ratio of large grains with $\varphi>40 \mathrm{~mm}$ was measured by means of particle digital image analysis, using vertical photographs that were taken from a height of approximately $1.5 \mathrm{~m}$ above the ground surface. All visible individual grains $>4.75 \mathrm{~mm}$ were outlined on the photographs, with the intermediate (b-axis) diameter and the cross-sectional area determined for each grain. For grains $<4.75 \mathrm{~mm}$, a $10 \mathrm{~kg}$ sample of $\leq 50 \mathrm{~mm}$ sediment was collected from each site and was sieved upon return to the laboratory. ASTM standards sieve series were utilized for this task. Assuming that the sediment has the same density, the weight percentages of grains with different grain sizes were calculated.

\section{Grain Size Distribution of Suspended Sediments}

The grain size distributions of suspended sediments were determined from samples collected from the three main rivers in the study area on the Min Jiang (Zhenjiangguan station), Tuo Jiang (Dengyingyan station) and Fu Jiang (Fujiangqiao station) (Fig. 1). The analyses were undertaken by the methods described in detail by Guy (1969) and the Ministry of Water Resources of China (2005) and a summary is provided here. A depth-integrated and channel averaged suspended sediment sample was collected. Calgon solution was added to disperse and disaggregate clay particles and the sample was sieved at $0.063 \mathrm{~mm}$. The $>0.063 \mathrm{~mm}$ fraction was oven-dried at 
$100^{\circ} \mathrm{C}$ and the grain size distribution was determined by dry sieving at $2 \mathrm{~mm}, 1 \mathrm{~mm}$, $0.5 \mathrm{~mm}, 0.25 \mathrm{~mm}$ and $0.125 \mathrm{~mm}$. The $<0.063 \mathrm{~mm}$ fraction was transferred to a $1 \mathrm{~L}$ graduated cylinder and was mixed for one minute until homogenized. Immediately after, $25 \mathrm{~mL}$ water was pipetted from the middle of cylinder to determine the total suspended load. Based on the predictable relationship between particle grain size and settling velocity in a fluid medium, the time and depth of subsequent pipette aliquots was determined on the basis of the Stokes law (e.g. for $25^{\circ} \mathrm{C}$, time $=1$ ' 43 ”, $\mathrm{D}=0.031$ $\mathrm{mm}$; time = 6'26”, $\mathrm{D}=0.016 \mathrm{~mm}$; time $=25^{\prime} 45^{\prime \prime}, \mathrm{D}=0.008 \mathrm{~mm}$; time $=1 \mathrm{~h} 43^{\prime}, \mathrm{D}=$ $0.004 \mathrm{~mm}$ ). The pipetted samples were dried and weighed. 
1 Table DR1. Landslide input and suspended sediment discharge of sixteen gauging stations along the Longmen Shan.

\begin{tabular}{|c|c|c|c|c|c|c|c|c|c|c|c|}
\hline Station & River & $\begin{array}{l}\text { Area } \\
\left(\mathrm{km}^{2}\right)\end{array}$ & $\begin{array}{c}\text { Runoff } \\
\left(\mathrm{mm} \mathrm{yr}^{-1}\right)\end{array}$ & $\begin{array}{l}\text { Proportion }>5 \\
\text { mm day }^{-1}(\%)\end{array}$ & $\begin{array}{c}Q_{\text {ss-pre }} \\
\left(\mathrm{Mt} \mathrm{yr}^{-1}\right)\end{array}$ & $\begin{array}{c}Q_{\text {ss-post }} \\
\left(\mathrm{Mt} \mathrm{yr}^{-1}\right)\end{array}$ & $\begin{array}{l}\text { Landslide } \\
\text { area }\left(\mathrm{km}^{2}\right)\end{array}$ & $\begin{array}{l}\text { Landslide } \\
\text { density (\%) }\end{array}$ & $\begin{array}{c}\text { Landslide input } \\
\text { (Mt) }\end{array}$ & $\begin{array}{r}M_{\text {fines }} \\
(\mathrm{Mt})\end{array}$ & $\begin{array}{l}T_{\text {fines }} \\
(\mathrm{yr})\end{array}$ \\
\hline Zhenjiangguan & Min J. & 4,486 & $350 \pm 76$ & 1.3 & $0.46 \pm 0.05$ & $0.64 \pm 0.06$ & $*$ & $*$ & $*$ & $*$ & - \\
\hline Heishui & Min J. & 1,720 & $773 \pm 84$ & 21.0 & $0.30 \pm 0.03$ & $0.30 \pm 0.03$ & 0.05 & $<0.01$ & $0.5+0.7 /-0.3$ & $0.03+0.05 /-0.03$ & $11+16 /-10$ \\
\hline Shaba & Min J. & 7,231 & $543 \pm 81$ & 5.4 & $1.55 \pm 0.16$ & $0.77 \pm 0.08$ & 0.23 & $<0.01$ & $2.1+2.0 /-0.9$ & $0.14+0.16 /-0.11$ & - \\
\hline Zagunao & Min J. & 2,404 & $808 \pm 83$ & 17.5 & $0.65 \pm 0.07$ & $0.53 \pm 0.05$ & 5.53 & 0.22 & $69+97 /-40$ & $5+7 /-4$ & - \\
\hline Sangping & Min J. & 4,629 & $673 \pm 74$ & 8.9 & $0.83 \pm 0.08$ & $1.06 \pm 0.11$ & 12.3 & 0.27 & $153+150 /-63$ & $10+12 /-8$ & $44+52 /-34$ \\
\hline Guojiaba & Min J. & 555 & $663 \pm 184$ & 48.7 & $0.10 \pm 0.01$ & $0.57 \pm 0.06$ & 9.71 & 1.71 & $84+101 /-46$ & $5+8 /-5$ & $12+16 /-10$ \\
\hline Dujiang & Min J. & 22,947 & $349 \pm 32$ & 0 & $0.39 \pm 0.04$ & $2.12 \pm 0.21$ & 163 & 0.71 & $2018+2529 /-1039$ & $133+189 /-112$ & $77+109 /-65$ \\
\hline Pingwu & Fu J. & 4,310 & $764 \pm 121$ & 13.7 & $1.38 \pm 0.14$ & $2.60 \pm 0.26$ & 5.02 & 0.12 & $85+147 /-53$ & $6+10 /-5$ & $5+9 /-4$ \\
\hline Jiangyou & Fu J. & 5,915 & $515 \pm 93$ & 17.2 & $1.59 \pm 0.16$ & $2.27 \pm 0.23$ & 8.37 & 0.14 & $125+158 /-58$ & $8+12 /-7$ & $12+17 /-10$ \\
\hline Ganxi & Fu J. & 1,067 & $509 \pm 102$ & 29.6 & $0.28 \pm 0.03$ & $1.36 \pm 0.14$ & 1.44 & 0.14 & $17+23 /-10$ & $1.1+1.7 /-1.0$ & $1.0+1.6 /-0.9$ \\
\hline Fujiangqiao & Fu J. & 11,903 & $644 \pm 105$ & 23.3 & $3.10 \pm 0.31$ & $14.50 \pm 1.45$ & 52.5 & 0.45 & $800+1282 /-486$ & $53+92 /-48$ & $5+8 /-4$ \\
\hline Zitong & Fu J. & 1,547 & $512 \pm 196$ & 66.0 & $0.27 \pm 0.03$ & $0.73 \pm 0.07$ & $*$ & $*$ & $*$ & $*$ & - \\
\hline Santai & Fu J. & 2,343 & $442 \pm 114$ & 33.2 & $0.07 \pm 0.01$ & $0.47 \pm 0.05$ & 20.2 & 0.79 & $1131+3056 /-816$ & $75+208 /-73$ & $190+528 /-186$ \\
\hline Pengshan & Min J. & 30,661 & $372 \pm 82$ & 8.9 & $1.09 \pm 0.11$ & $4.14 \pm 0.41$ & 172 & 0.56 & $2125+2534 /-1040$ & $140+192 /-116$ & $46+63 /-38$ \\
\hline Dengyingyan & Tuo J. & 14,484 & $583 \pm 113$ & 25.3 & $1.61 \pm 0.16$ & $4.58 \pm 0.46$ & 109 & 0.74 & $1789+2933 /-1096$ & $118+209 /-107$ & $40+70 /-36$ \\
\hline Shehong & Fu J. & 23,574 & $480 \pm 87$ & 25.0 & $1.46 \pm 0.15$ & $9.78 \pm 0.98$ & 109 & 0.47 & $2415+3386 /-991$ & $159+247 /-125$ & $19+30 /-15$ \\
\hline Total & - & 68,719 & $478 \pm 126$ & - & $4.56 \pm 0.46$ & $18.50 \pm 1.85$ & 390 & 0.57 & $6329+5097 /-1787$ & $418+437 /-302$ & $29+30 /-21$ \\
\hline
\end{tabular}

2 *Negligible landslide coverage.

3 The runoff is based on the time period of 2006-2012 except Sangping station (2006-2011). $Q_{\text {ss-pre }}$ and $Q_{\text {ss-post }}$ are the average annual suspended sediment discharges before (2006-2007) and after (2008-2012) the

4 earthquake, respectively. $M_{\text {fines }}\left(\mathrm{Mt}\right.$ ) is the estimated mass of landslide material with a grain size $<0.25 \mathrm{~mm}$, which accounts for $4-9 \%$ of the total landslide mass. $T_{\text {fines }}$ (yr) is the estimated time necessary for rivers to

5 remove all $M_{\text {fines }}$ based on the post-earthquake removal rates. 
6 Table DR2. Uncertainty of suspended-sediment discharge at the Sangping station.

\begin{tabular}{cccc}
\hline Year & $\boldsymbol{n}$ & Standard Deviation $(\boldsymbol{\%})$ & Standard Error $(\boldsymbol{\%})$ \\
\hline $\mathbf{2 0 0 6}$ & 113 & 12.6 & 5.1 \\
$\mathbf{2 0 0 7}$ & 112 & 12.3 & 5.8 \\
$\mathbf{2 0 0 8}$ & 158 & 6.1 & 3.3 \\
$\mathbf{2 0 0 9}$ & 117 & 8.1 & 4.6 \\
total & 500 & 10.1 & 4.9 \\
\hline
\end{tabular}

$7 n$ is the number of days with more than one SSC measurement. The standard deviation and 8 standard error are reported as a percentage of the mean SSC.

9

10

11

12

13

14

15

16

17

18

19

20

21

22

23

24

25

26

27

28

29

30

31

32 
44 Table DR3. Proportion of grains $<0.25 \mathrm{~mm}$ from deposits of landslides triggered by the Wenchuan 45 earthquake.

\begin{tabular}{|c|c|c|c|}
\hline Site & Catchment & Weight $\%<0.25 \mathrm{~mm}$ & Reference \\
\hline Xiaojiagou, Yingxiu S1 & Min Jiang & $3.0 \%$ & 1 \\
\hline Xiaojiagou, Yingxiu S2 & Min Jiang & $6.0 \%$ & 1 \\
\hline Xiaojiagou, Yingxiu S3 & Min Jiang & $3.0 \%$ & 1 \\
\hline Xiaojiagou, Yingxiu S4 & Min Jiang & $3.0 \%$ & 1 \\
\hline Xiaojiagou, Yingxiu S5 & Min Jiang & $3.0 \%$ & 1 \\
\hline Xiaojiagou, Yingxiu S6 & Min Jiang & $3.0 \%$ & 1 \\
\hline Xiaojiagou, Yingxiu S7 & Min Jiang & $3.0 \%$ & 1 \\
\hline Xiaojiagou, Yingxiu S8 & Min Jiang & $5.0 \%$ & 1 \\
\hline Niuquangou - a & Min Jiang & $8.2 \%$ & 2 \\
\hline Niuquangou - b & Min Jiang & $7.0 \%$ & 2 \\
\hline Niuquangou - c & Min Jiang & $10.3 \%$ & 2 \\
\hline Xiejiadianzi - a & Tuo Jiang & $6.4 \%$ & 2 \\
\hline Xiejiadianzi - b & Tuo Jiang & $5.1 \%$ & 2 \\
\hline Xiejiadianzi - c & Tuo Jiang & $6.0 \%$ & 2 \\
\hline Xiejiadianzi - d & Tuo Jiang & $1.2 \%$ & 2 \\
\hline Wenjiagou - a & Tuo Jiang & $5.3 \%$ & 2 \\
\hline Wenjiagou - b & Tuo Jiang & $2.8 \%$ & 2 \\
\hline Wenjiagou - c & Tuo Jiang & $8.8 \%$ & 2 \\
\hline Wenjiagou - $\mathrm{d}$ & Tuo Jiang & $2.6 \%$ & 2 \\
\hline Mianyuan River, p6 & Tuo Jiang & $3.8 \%$ & 3 \\
\hline Mianyuan River, p9 & Tuo Jiang & $5.2 \%$ & 3 \\
\hline Mianyuan River, p7 & Tuo Jiang & $7.4 \%$ & 3 \\
\hline Mianyuan River, p11 & Tuo Jiang & $9.6 \%$ & 3 \\
\hline Mianyuan River, p5 & Tuo Jiang & $10.8 \%$ & 3 \\
\hline Mianyuan River, p10 & Tuo Jiang & $13.4 \%$ & 3 \\
\hline Wenjiagou, site 1 & Tuo Jiang & $2.0 \%$ & 4 \\
\hline Wenjiagou, site 2 & Tuo Jiang & $22.9 \%$ & 4 \\
\hline Shiting River & Tuo Jiang & $6.1 \%$ & 5 \\
\hline Qingzhu River & Fu Jiang & $4.3 \%$ & 5 \\
\hline Weijiagou, site 1 & Fu Jiang & $6.1 \%$ & 6 \\
\hline Weijiagou, site 2 & Fu Jiang & $6.7 \%$ & 6 \\
\hline Weijiagou, site 3 & Fu Jiang & $8.7 \%$ & 6 \\
\hline Weijiagou, site 4 & Fu Jiang & $16.8 \%$ & 6 \\
\hline Average $(n=33)$ & & $6.6 \pm 4.4 \%$ & \\
\hline
\end{tabular}

References: 1, Chen et al., 2012; 2, Wang et al., 2012; 3, Wang et al., 2013; 4, Yu et al., 2013; 5,

47 Wang et al., 2011; 6, Zhuang et al., 2012. 

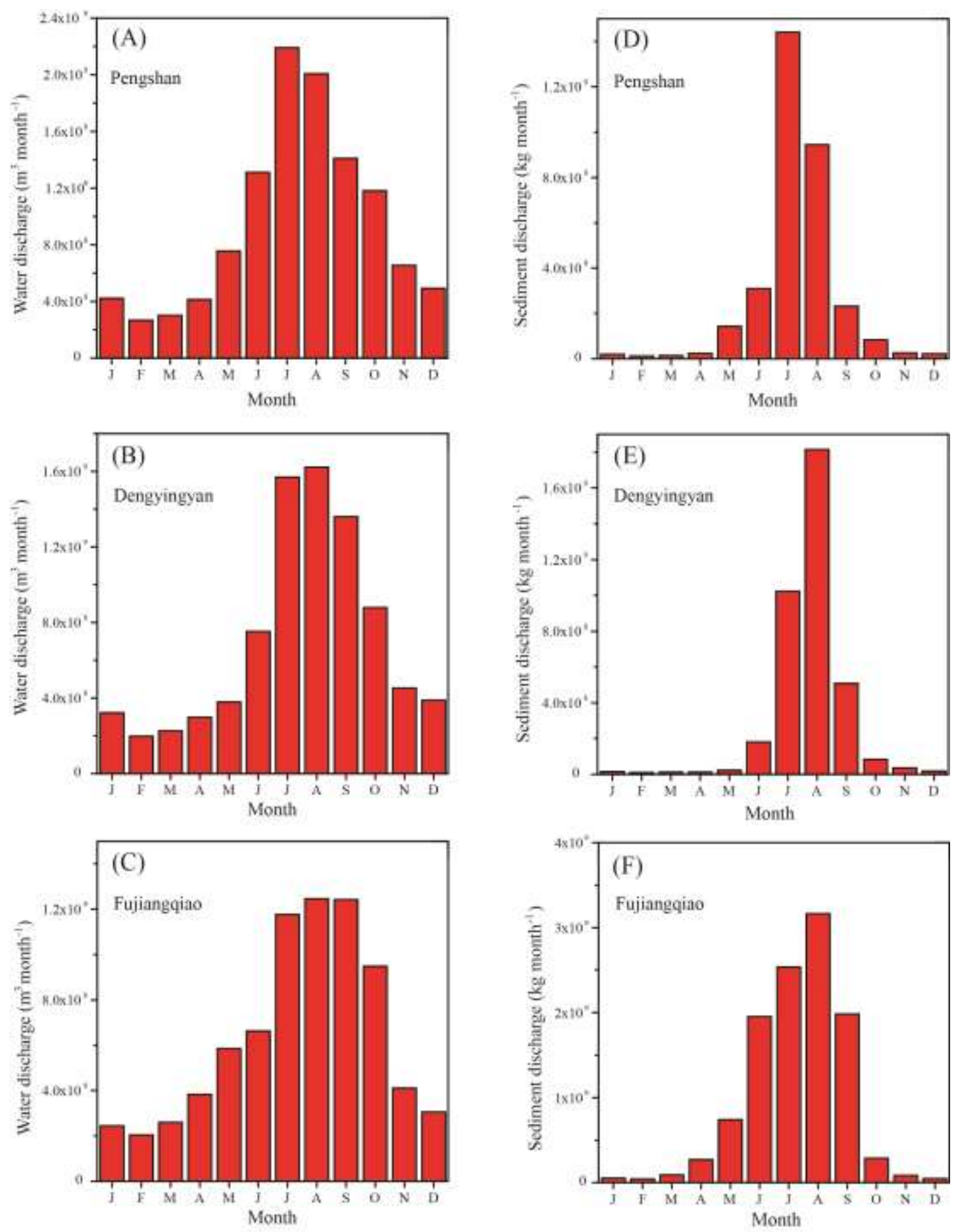

48

Figure DR1: Monthly variations of water discharge $\left(\mathrm{m}^{3} \mathrm{month}^{-1}\right)$ and suspended sediment discharge $\left(\mathrm{kg} \mathrm{month}^{-1}\right)$ at three typical stations across the Longmen Shan from 2006 to 2012. (A and D) Pengshan station, (B and E) Dengyingyan station, and (C and F) Fujiangqiao station. Water discharge during April to October accounts for $\sim 81 \%$ of total annual discharge, whereas suspended sediment discharge accounts for $\sim 97 \%$ at these stations. 


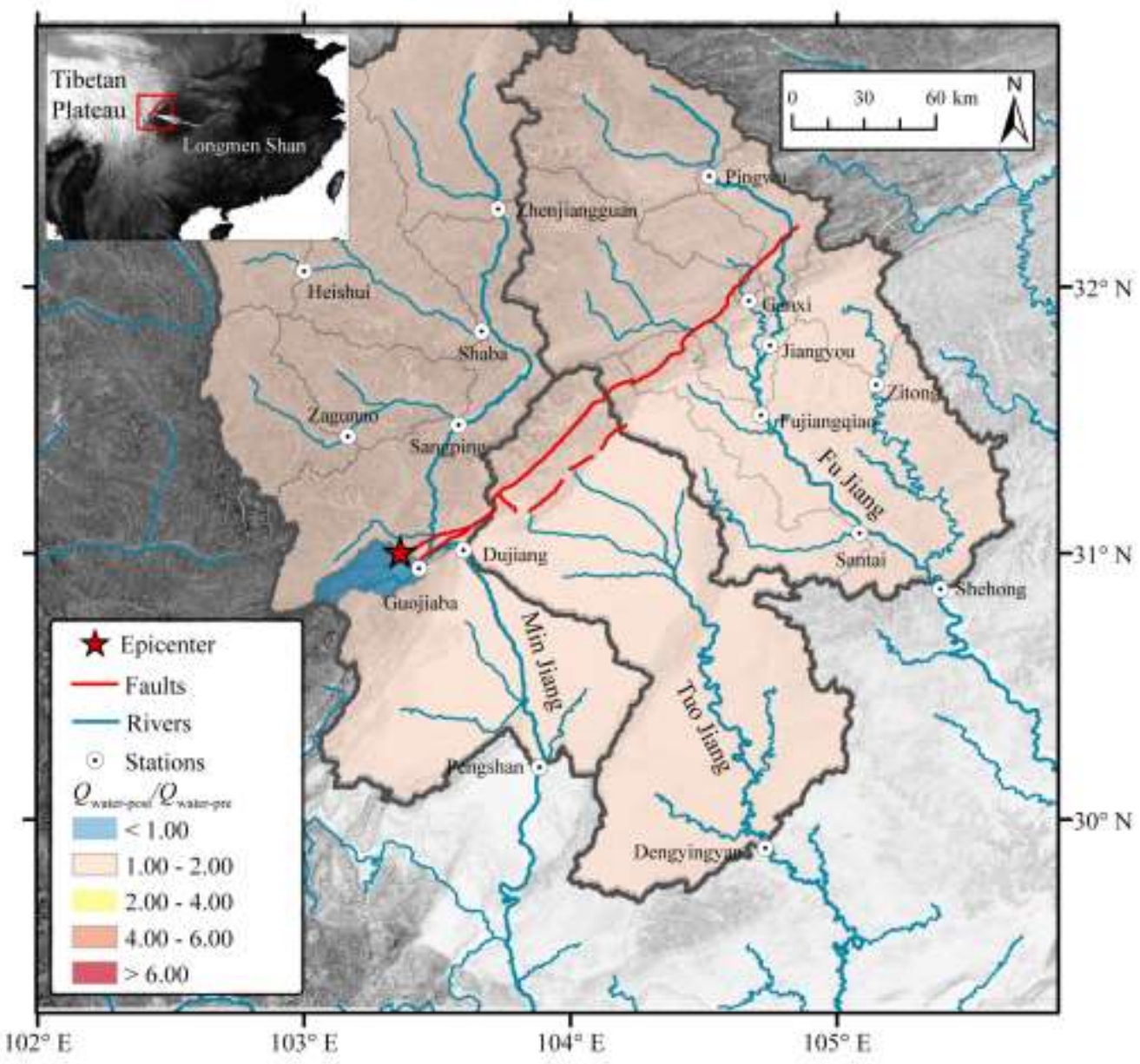

Figure DR2: Water discharge enhancement in rivers of the Longmen Shan following the Wenchuan earthquake. Catchment shadings reflect the ratios of mean annual water discharge $\left(Q_{\text {water }}, \mathrm{m}^{3} \mathrm{yr}^{-1}\right)$ after the Wenchuan earthquake to that prior to the earthquake for available gauging stations (circles). In order to compare with the ratios of suspended sediment enhancement in Fig. 1, we use the same class ranges for colour shadings. The large discrepancy between the water discharge enhancement (shown here) and the suspended sediment enhancement (Fig. 1) demonstrates that the changes of sediment load are not caused by variation in water discharge. 
A Upstream: Zagunao Downstream: Sangping

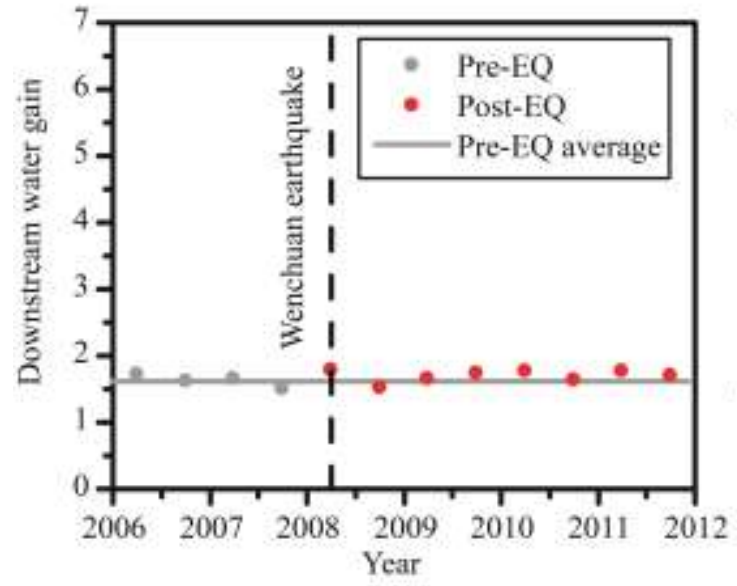

B Upstream: Pingwu Downstream: Fujiangqiao

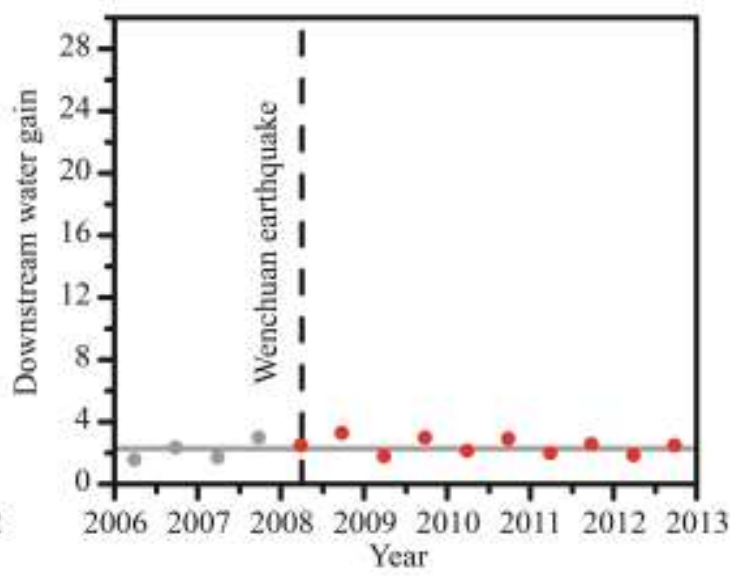

Figure DR3: A. Downstream water gain for nested gauging stations on the Zagunao River. B. Downstream water gain for nested gauging stations on the Fu Jiang. Downstream water gain is the ratio of downstream to upstream water discharge. In order to compare with the downstream sediment gain in Fig. $2 \mathrm{~B}$ and $2 \mathrm{C}$, we use the same ranges of axes.

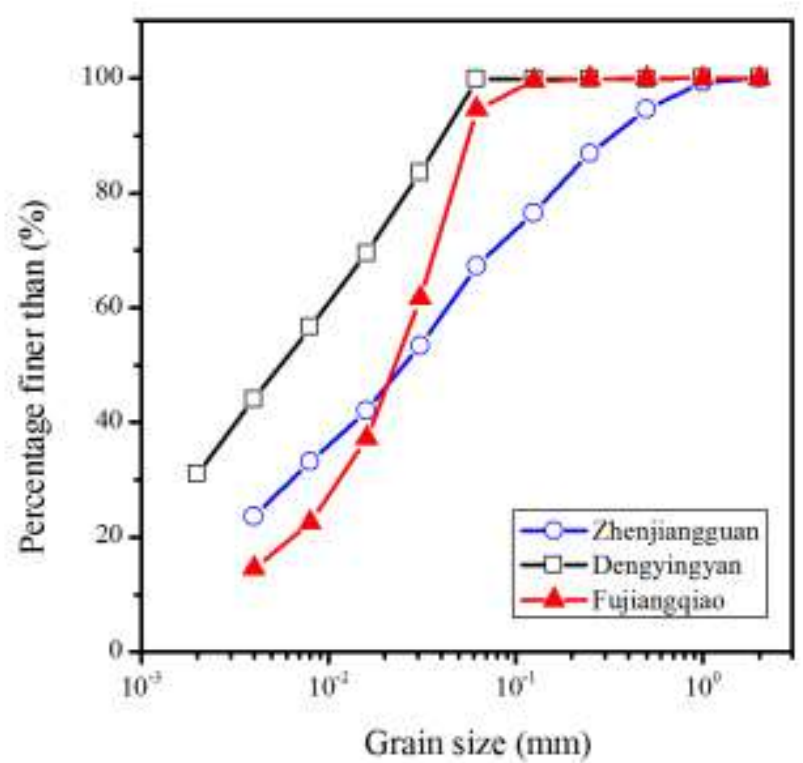

Figure DR4: Grain size distribution of suspended sediment in our studied rivers during 2007 to 2012. Over $95 \%$ of suspended sediment grain size is smaller than 0.25 $\mathrm{mm}$. The blue line with open circles is grain size distribution of suspended sediment collected from Zhenjiangguan station on the Min Jiang; black line with squares is from Dengyingyan station on the Tuo Jiang; and the red line with triangles is from Fujiangqiao station on the $\mathrm{Fu}$ Jiang. The method for determining the grain size distribution followed the standard of the Ministry of Water Resources of China (2005). 

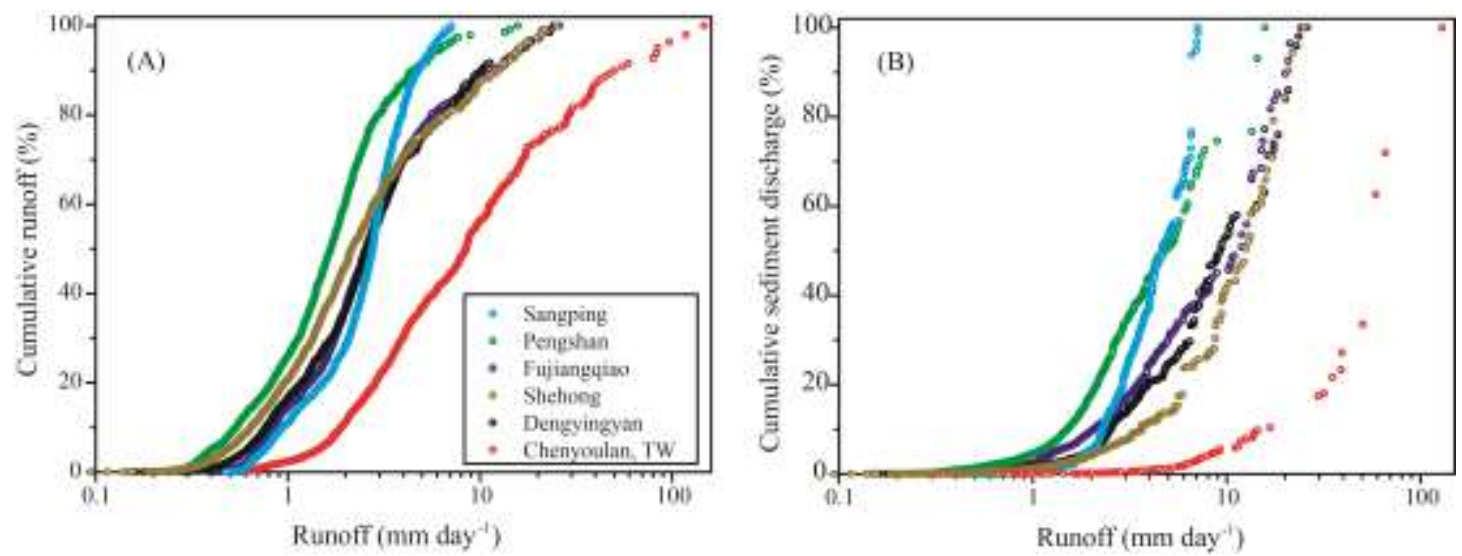

Figure DR5: The cumulative runoff $(A)$ and sediment discharge $(B)$ in Longmen Shan and in the Chenyoulan River, Taiwan after the Wenchuan and Chi-Chi earthquakes. Comparing to the rivers in the Longmen Shan, the Chenyoulan River has higher runoff, with higher frequency of high runoff events. Most of suspended sediment is mobilized during high runoff events.

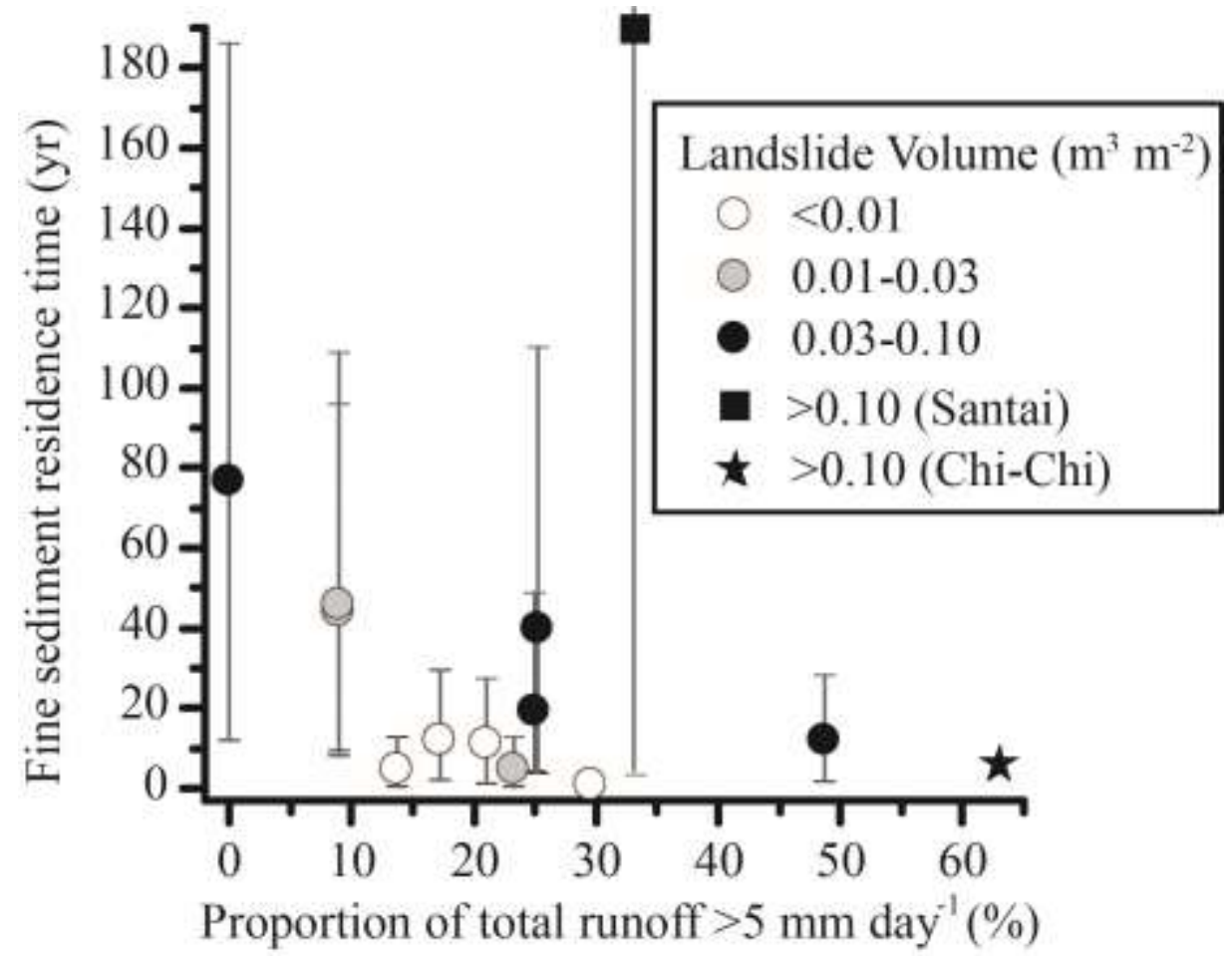

Figure DR6: Estimates of residence time of fine grained sediment mobilized by earthquake-triggered landslides in river catchments impacted by Wenchuan earthquake, plotted as a function of proportion of catchment intense runoff ( $>5$ mm day ${ }^{-1}$ ). Compared to Fig. 3, the symbols reflect the landslide volume per unit area caused by coseismic landslide. The residence time of Santai station (square, landslide density $=0.79 \%$ ) is not well explained by the control of landslide density in Fig. 3. This is because there are some individual landslides with large volume, which contribute significant volumes of sediment, but this is not reflected in landslide area in this small $\left(2,300 \mathrm{~km}^{2}\right)$ catchment. 


\section{References cited:}

Chen, H.X., Zhang, L.M., Chang, D.S., and Zhang, S., 2012, Mechanisms and runout characteristics of the rainfall-triggered debris flow in Xiaojiagou in Sichuan Province, China: Natural Hazards, v. 62, p. 1037-1057, doi: 10.1007/s11069-012-0133-5.

Guy, H.P., 1969, Laboratory theory and methods for sediment analysis: U.S. Geological Survey Techniques of Water Resources Investigations, book 5, chap. C1, p. 23-28.

Ministry of Water Resources of China, 2005, Technical Standard for Determination of Sediment Particle Size in Open Channels (SL 42-2010): Beijing, China Water and Power Press (in Chinese).

Wang, G., Huang, R., Kamai, T., and Zhang, F., 2013, The internal structure of a rockslide dam induced by the 2008 Wenchuan $\left(M_{w} 7.9\right)$ earthquake, China: Engineering Geology, v. 156, p. 28-36, doi: 10.1016/j.enggeo.2013.01.004.

Wang, Y., Cheng, Q., and Zhu, Q., 2012, Inverse grading analysis of deposit from rock avalanches triggered by wenchuan earthquake: Chinese Journal of Rock Mechanics and Engineering, v. 31, p. 1089-1106 (in Chinese).

Wang, Z., Shi, W., and Liu, D., 2011, Continual erosion of bare rocks after the Wenchuan earthquake and control strategies: Journal of Asian Earth Sciences, v. 40, p. 915-925, doi: 10.1016/j.jseaes.2010.07.004.

Yu, B., Ma, Y., and Wu, Y., 2013, Case study of a giant debris flow in the Wenjia Gully, Sichuan Province, China: Natural Hazards, v. 65, p. 835-849, doi: 10.1007/s11069-012-0395-y.

Zhuang, J., You, Y., Chen, X., and Pei, L., 2012, Effect of infiltration and anti-scourability of mixed-grain-sized, unconsolidated soil on debris flow initiation: Bulletin of Soil and Water Conservation, v. 32, p. 43-47 (in Chinese). 